\title{
Application of Struvite Alters the Antibiotic Resistome in Soil, Rhizosphere, and Phyllosphere
}

\author{
Qing-Lin Chen, ${ }^{\dagger, \dagger}$ Xin-Li An, ${ }^{\dagger, \dagger}$ Yong-Guan Zhu, ${ }^{\dagger, \S \odot ~ J i a n-Q i a n g ~ S u, ~}{ }^{\dagger}$ Michael R. Gillings, ${ }^{\|}$Zhi-Long Ye, \\ and $\mathrm{Li} \mathrm{Cui}{ }^{*}+$ 이
}
${ }^{\dagger}$ Key Laboratory of Urban Environment and Health, Institute of Urban Environment, Chinese Academy of Sciences, 1799 Jimei Road, Xiamen 361021, China
*University of Chinese Academy of Sciences, 19A Yuquan Road, Beijing 100049, China
${ }^{\S}$ State Key Laboratory of Urban and Regional Ecology, Research Center for Eco-Environmental Sciences, Chinese Academy of Sciences, Beijing 100085, China
"Department of Biological Sciences, Macquarie University, Sydney, New South Wales 2109, Australia

\section{Supporting Information}

ABSTRACT: Struvite recovered from wastewater is a renewable source of phosphorus and nitrogen and can be used as fertilizer for plant growth. However, antibiotics and resistome can be enriched in the struvite derived from wastewater. Robust understanding of the potential risks after struvite application to soils has remained elusive. Here, we profiled antibiotic resistance genes (ARGs) and mobile genetic elements (MGEs) in struvite, soil, rhizosphere and phyllosphere of Brassica using high-throughput quantitative PCR. A total of 165 ARGs and 10 MGEs were detected. Application of struvite was found to increase both the abundance and diversity of ARGs in soil, rhizosphere and phyllosphere. In addition, ARGs shared exclusively between Brassica phyllosphere and struvite were identified, indicating that struvite was an important source of ARGs found in

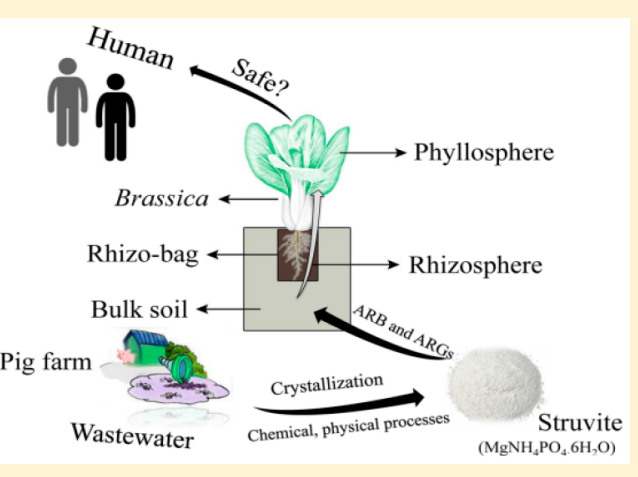
phyllosphere. Furthermore, OTUs shared between rhizosphere and phyllosphere were found to significantly correlate with ARGs, suggesting that microbiota in leaf and root could interconnect and ARGs might transfer from struvite to the surface of plants via rhizosphere using bacteria as spreading medium. These findings demonstrated that struvite as an organic fertilizer can facilitate the spread of antibiotic resistance into human food chain and this environment-acquired antibiotic resistance should be put into human health risk assessment system.

\section{INTRODUCTION}

Antibiotic resistance is a global public health concern. $^{1-3}$ Extensive application of organic fertilizers such as animal manures and sewage sludge in agriculture is exacerbating this problem. ${ }^{4-6}$ Organic fertilizer is a rich source of nutrients and organic matter for crop growth. However, previous works have identified organic fertilizer as reservoirs of high levels of antibiotics, antibiotic resistant bacteria (ARB), and antibiotic resistant genes (ARGs), all of which can further enter and be enriched in soil amended with organic fertilizer. ${ }^{5,7-9}$ More seriously, abundant ARGs have been found in various crops harvested in organically fertilized soil. For example, additional ARGs were identified in tomato and carrot after application of swine manure and sewage sludge. ${ }^{10,11}$ Our previous study also suggested that organically produced lettuce harbored higher abundance of ARGs than conventionally produced. ${ }^{12}$ These ARGs can potentially enter food chain via contaminated crops, or even to human pathogens via horizontal gene transfer, posing a high risk to human health. ${ }^{13,14}$ However, it remains elusive how ARGs in organic fertilizer are finally transferred to crops. To understand this process, it is necessary to investigate the resistome in the transferring media involved in the whole pathway including organic fertilizer, soil, rhizosphere, and phyllosphere.

In addition to conventional organic fertilizers used for nutrient cycling, struvite $\left(\mathrm{MgNH}_{4} \mathrm{PO}_{4} \cdot 6 \mathrm{H}_{2} \mathrm{O}\right)$ is considered as an alternative way to recover phosphorus $(\mathrm{P})$ and nitrogen $(\mathrm{N})$ from wastewater, and can be used as $\mathrm{P}$ and $\mathrm{N}$ fertilizers for agricultural soils. ${ }^{15-18} \mathrm{P}$ is an essential element for plant growth but has limited reserve on the earth. The only source is phosphate rock which is nonrenewable and becoming depleted due to growing demand by both agriculture and industry. ${ }^{19,20}$ Meanwhile, substantial amount of $\mathrm{P}$ is being discharged into water bodies from a wide range of human activities, and the excessive $\mathrm{P}$ is causing nutrient pollution such as eutrophication. $^{21}$ Recovery of $\mathrm{P}$ in an economical way can not only replenish agricultural soils for sustainable food production, but

Received: March 17, 2017

Revised: June 3, 2017

Accepted: June 19, 2017

Published: June 19, 2017 
also mitigate the global crisis of $\mathrm{P}$ depletion. ${ }^{19}$ Struvite crystallization is an efficient process to recover phosphate from wastewater. ${ }^{22-24}$ Presently, struvite production has been commercialized worldwide and the sale price is approximately \$198-1885 per ton in Australia and Japan. ${ }^{25,26}$ Struvite could be a promising fertilizer with the depletion of phosphate rock, and its usage in agriculture is likely to increase in the near future.

Wastewater, especially those from livestock industries, has been well documented to be a hotspot of antibiotic resistance. ${ }^{27-30}$ Therefore, struvite recovered from wastewater could be contaminated by ARGs, ARB, and antibiotic residues. ${ }^{31}$ The use of struvite as fertilizer and subsequent consumption of crops grown in struvite-fertilized soil represent a potential source of human exposure to ARGs. However, a robust understanding of the potential risk of using struvite as fertilizer in agriculture remains elusive.

In the present study, by using high throughput qPCR with 296 validated primer sets targeting almost all major classes of ARGs and 10 MGEs marker genes, ${ }^{32}$ and illumina sequencing of bacterial 16S rRNA gene, we aimed to (1) investigate the impact of struvite application on the profile of ARGs and bacterial communities in soil, rhizosphere and phyllosphere of Brassica; (2) reveal the shared ARGs between struvite, soil and phyllosphere based on bipartite network analysis; and (3) explore how antibiotic resistance in struvite transferred to the surface of plants. The outcome will provide important information for the sustainable and safe use of organic fertilizer in agriculture.

\section{MATERIALS AND METHODS}

Materials and Properties. Struvite was obtained from swine wastewater (anaerobic digester) in a large piggery operated by Yinxiang Group (Xiamen, China). Detailed information about struvite crystallization is described elsewhere. ${ }^{33}$ The struvite was air-dried without further pretreatments prior to being used as fertilizer. Soils used for pot experiments were collected from a vegetable field, which had never been amended with struvite previously or treated with other organic fertilizers in recent three years. Soils were airdried and passed through a $2 \mathrm{~mm}$ mesh sieve before use. Chemical properties of struvite and soil are listed in Supporting Information (SI) Table S1, including the concentration of nutrients (total carbon and total nitrogen), heavy metals, and/ or antibiotics. Nutrients were measured via dry combustion in a $\mathrm{C} / \mathrm{N}$ instrument (Vario MAX C/N; Elementar). Soil $\mathrm{pH}$ was determined by preparing a 1:2.5 soil/water $(\mathrm{w} / \mathrm{v})$ suspension. Metals were measured by inductively coupled plasma-mass spectrometry (ICP-MS, $7500 \mathrm{cx}$, Agilent) after oxidative digestion of air-dried and milled samples in sealed tubes. Concentrations of antibiotics in struvite were analyzed by liquid chromatography-MS/MS (ABI 3200 Q TRAP). More detailed procedure for sample extraction and analysis of metals and antibiotics can be found in previous studies. ${ }^{32,34}$ The abundance of $16 \mathrm{~S}$ rRNA gene and ARGs in struvite was determined to be $2.45 \times 10^{11}$ and $4.87 \times 10^{11}$ copies/g soil (dry weight) respectively using the procedure about DNA extraction and quantification described below.

Experiment Design. SI Figure S1 shows the schematic of experimental design. Soils were amended with or without $0.2 \%$ struvite $(\mathrm{w} / \mathrm{w}) .{ }^{35}$ The obtained soils were then planted or not planted with Brassica. Each plastic pot contained $3.0 \mathrm{~kg}$ soil and each treatment was performed in triplicate. In the pots planting
Brassica, a rhizo-bag (containing $500 \mathrm{~g}$ soil) that allowed smaller molecular substrates to penetrate but prohibited penetration by roots, ${ }^{36}$ was used to separate rhizosphere from bulk soils. Seeds of Brassica were germinated and grown for 7 days in moist perlite before transplanting one plant into each designated pot. All pots were incubated in a greenhouse with natural illumination and humidity at a temperature of $25 \pm 2$ ${ }^{\circ} \mathrm{C}$ during the day and $20 \pm 2{ }^{\circ} \mathrm{C}$ in the night. Initial soil moisture content was adjusted to $70 \%$ of water-holding capacity $^{37}$ and deionized water was added to maintain the soil water content every 2 days. Plants were harvest after 60 days. A total of four types of samples were collected, including nonplanted soil, bulk soil, rhizosphere soil, and phyllosphere of Brassica.

Extraction of DNA from Soil and Vegetables. A FastDNA Spin Kit for Soil (MP Biomedicals, CA) was used to extract total DNA from $0.5 \mathrm{~g}$ of each soil sample. ${ }^{13}$ Total phyllosphere DNA was extracted according to previous methods. ${ }^{12,38}$ Briefly, around $5 \mathrm{~g}$ leaf tissue was weighed into a conical flask $(250 \mathrm{~mL})$ containing $100 \mathrm{~mL}$ of $0.01 \mathrm{M}$ phosphate-buffered saline (PBS). The mixture was sonicated for $7 \mathrm{~min}$ and shaken at $180 \mathrm{rpm}$ at $30^{\circ} \mathrm{C}$ for $1 \mathrm{~h}$. The obtained solution was filtered with nylon gauze and then a $0.22 \mu \mathrm{M}$ cellulose membrane, and the filtrate was then subjected to DNA extraction using FastDNA Spin Kit for Soil. To determine the concentration and quality of the extracted DNA, spectrophotometer analysis (NanoDrop ND-1000, Thermo Scientific, Waltham, MA) and $1.0 \%$ agarose gel electrophoresis was used. DNA was stored at $-20{ }^{\circ} \mathrm{C}$ until use.

ARG Quantification Using High-Throughput Quantitative PCR. High-throughput qPCR was performed using the Wafergen SmartChip Real-time PCR system (Wafergen, Fremont, CA). This SmartChip platform can be used for large-scale analysis by processing 5184-nanowell reactions per run. A total of 296 primer sets were used in the present study, targeting 285 ARGs (almost all major classes of ARGs), 8 transposases, class 1 intergron, clinical class 1 integron and the $16 \mathrm{~S}$ rRNA gene. ${ }^{5}$ PCR mixtures $(100 \mathrm{~nL}$ per well) consisted of $1 \times$ LightCycler 480 SYBR Green I Master, nuclease-free PCRgrade water, $20 \mathrm{mg} / \mathrm{mL}$ bovine serum albumin, $500 \mathrm{nM}$ each primer and $50 \mathrm{ng} / \mu \mathrm{L}$ DNA template. The initial enzyme activation was performed at $95{ }^{\circ} \mathrm{C}$ for $10 \mathrm{~min}$, and then 40 cycles of the following program were used for amplification: denaturation at $95{ }^{\circ} \mathrm{C}$ for $30 \mathrm{~s}$, annealing at $60{ }^{\circ} \mathrm{C}$ for $30 \mathrm{~s}$. Melting process was automatically generated by Wafergen software. qPCR results were analyzed using SmartChip qPCR Software. Wells with multiple melting peaks or with amplification efficiencies beyond the range $(1.8-2.2)$ were discarded. A threshold cycle $\left(C_{\mathrm{T}}\right)$ of 31 was used as the detection limit, ${ }^{32}$ and only ARGs with amplification in all replicates were regarded as positive. Relative copy number was calculated according to eq 1,5 and transformed to absolute copy number by normalization with $16 \mathrm{~S}$ rRNA gene copy numbers quantified by Roche 480 using a SYBR Green approach separately. To minimize potential variation in DNA extraction and analytical efficiencies as well as background bacterial abundance, the abundance of ARGs was normalized by $16 \mathrm{~S}$ rRNA and transformed into ARGs copies per cell. The average number of $16 \mathrm{~S}$ rRNA gene per bacterium is currently estimated at 4.1 based on the Ribosomal RNA Operon Copy Number Database. ${ }^{39,40}$

$$
\text { relative gene copy number }=10^{\left(31-C_{\mathrm{T}}\right) /(10 / 3)}
$$


Illumina Sequencing, Data Processing, and Analysis. To characterize the bacterial community structure and composition, the hypervariable V4-V5 region of bacterial $16 \mathrm{~S}$ rRNA was selected for amplification with primers 515F: GTGCCAGCMGCCGCGG and 907R: CCGTCAATCMTTTRAGTTT. ${ }^{41}$ In order to distinguish samples, the reverse primer was tagged with unique barcodes. ${ }^{42}$ The initial enzyme activation was performed at $95{ }^{\circ} \mathrm{C}$ for $5 \mathrm{~min}$, and then 35 cycles of the following program were used for amplification: $95^{\circ} \mathrm{C}$ for $30 \mathrm{~s}, 58{ }^{\circ} \mathrm{C}$ for $30 \mathrm{~s}$ and $72{ }^{\circ} \mathrm{C}$ for $30 \mathrm{~s}$. Sequencing of these barcoded amplicons was performed using the Illumina Hiseq2500 platform (Novogene, Beijing, China). The raw pair-end reads were assembled after filtering of adaptor, lowquality reads, ambiguous nucleotides, and barcodes to generate clean joined reads capturing the complete V4-V5 region of the 16S rRNA gene. Quantitative Insights Into Microbial Ecology (QIIME) was used for further data processing. ${ }^{43}$ The openreference operational taxonomic unit (OTU) picking was performed following the online instructions in QIIME. OTUs were defined at a $97 \%$ similarity level using UCLUST. ${ }^{44}$ Taxonomic classification and quantification of OTUs were performed against the Greengenes version 13.5 16S rRNA database. ${ }^{45,46}$ Global singletons were removed and sequences were aligned using a PyNAST aligner, ${ }^{47}$ and a phylogenetic tree was built using the Fasttree algorithm, ${ }^{48}$ prior to downstream analysis. All sequences were deposited in the National Center for Biotechnology Information Sequence Read Archive under the accession number SRP108151. Alpha-diversity was described for each sample using the metrics observed species (OTU numbers), Chao1, Shannon index, and PD Whole tree and rarefaction curves were generated to compare the level of bacterial OTU diversity. The beta-diversity of different samples was compared using principal coordinate analysis (PCoA) based on Bray-Curtis distance.

Statistical Analysis. All mathematical operations (Sum, average etc.) on the raw data were conducted in $R^{49}$ Significance tests were performed using SPSS Software (PASW Statistics 20.0). All statistical tests were considered significant at $P<0.05$. PCoA based on Bray-Curtis distance was utilized to evaluate ARGs and bacterial community profiles between different treatments using Canoco software (V 5.0). Adonis test, Mantel test, Procrustes test for correlation analysis between ARGs and bacterial communities were performed in $\mathrm{R}$ with the vegan package. ${ }^{50}$ The Gephi (V 0.9.1) software was used to visualize the bipartite network graphs using the Force Atlas algorithm.

\section{RESULTS}

Diversity and Abundance of Antibiotic Resistance Genes. A total of 165 ARGs and 10 MGEs were detected in soil samples and struvite. The detected number of ARGs and MGEs ranged from 40 to 114 in each sample, with struvite and bulk soil harboring the highest (114) and lowest (40) diversity of ARGs (Figure 1). ARGs were classified into 8 types (i.e., aminoglycoside, beta-lactams, macrolide-lincosamide-streptogramin B (MLSB), multidrug, sulfonamide, tetracycline, vancomycin, and others) based on the class of antibiotics they resisted. Genes for beta-lactams resistance, multidrug efflux and MLSB were the most common types of ARGs. The number of ARGs and MGEs increased in all samples when struvite (S) was added, including nonplanted soil (C), bulk soil (B), rhizosphere soil (R), and phyllosphere (P). PCoA analysis based on Bray-Curtis (SI Figure S2) showed that the profiles

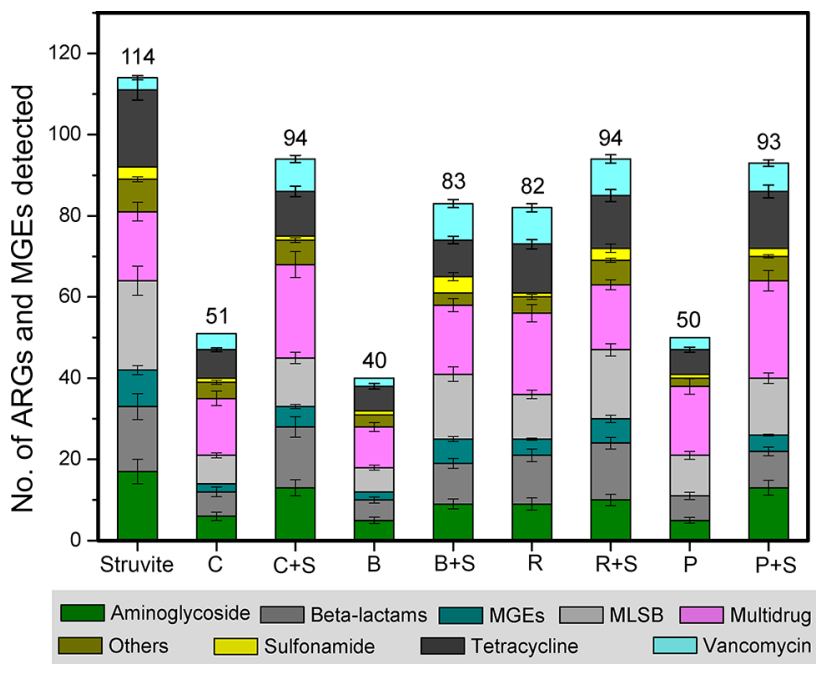

Figure 1. Detected number of ARGs and MGEs in soil (including nonplanted soil, bulk soil and rhizosphere soil), Brassica phyllosphere and struvite. ARGs were classified based on the antibiotic they resisted. $\mathrm{S}$, struvite; C, nonplanted soil; $\mathrm{C}+\mathrm{S}$, nonplanted soil amended with struvite; B, bulk soil; $\mathrm{B}+\mathrm{S}$, bulk soil amended with struvite; $\mathrm{R}$, rhizosphere soil; $\mathrm{R}+\mathrm{S}$, rhizosphere soil amended with struvite; $\mathrm{P}$, Brassica phyllosphere; $\mathrm{P}+\mathrm{S}$, Brassica phyllosphere planted in soil amended with struvite. Data from three replicates $(n=3)$ are represented as means $\pm \mathrm{SD}$.

of ARG in phyllosphere were obviously different from soils (Adonis, $P<0.01$ ). In addition, the unamended soils separated well from struvite-amended soil, regardless of Brassica plantation, indicating that application of struvite significantly altered ARG compositions in soil (Adonis, $P<0.01$ ).

The absolute abundance of ARGs in soil and phyllosphere ranged from $3.25 \times 10^{9}$ to $1.26 \times 10^{10}$ and from $7.57 \times 10^{7}$ to $5.95 \times 10^{8}$ copies $\mathrm{g}^{-1}$ solid dry weight, respectively (SI Figure S3). Because soil samples harbored more bacterial cells than phyllosphere, in order to minimize potential variations in background bacterial abundances among different samples, the absolute abundance of ARG and MGE marker genes were normalized to $16 \mathrm{~S}$ rRNA genes (Figure 2). It is clear that struvite amendment consistently raised the normalized abundance of both ARGs and MGEs in soil, rhizosphere and phyllosphere. In addition, we observed that rhizosphere soil harbored more resistome than bulk soil, and the abundance of MGEs in phyllosphere was much lower than that in soil. In addition to the abundance and diversity of ARGs, the cooccurrence pattern of ARG was also alerted, with more interactions (links) being observed in the network after application of struvite (SI Figure S4, Table S2).

Shared Resistome between Struvite, Soil, and Phyllosphere. Analysis of shared resistome provided a way to track the origin of ARGs. ARGs shared between struvite, soil, and phyllosphere and those exclusively detected in each sample were displayed using a bipartite network analysis (Figure 3). Seven categories were identified with the last two being of the major concern. They are described clockwise: (i) forty-four genes unique to struvite, since these genes do not colonize in soil or plants and are thus of little concern; (ii) 13 ARGs shared by soil and struvite but not in plants are again of little concern; (iii) a single outlier $(m t r C)$ only found in soil is again of little concern; (iv) ten ARGs already in the soil that also find their way onto the phyllosphere are of possible concern, but struvite is not responsible for their presence; (v) 25 ARGs and a 


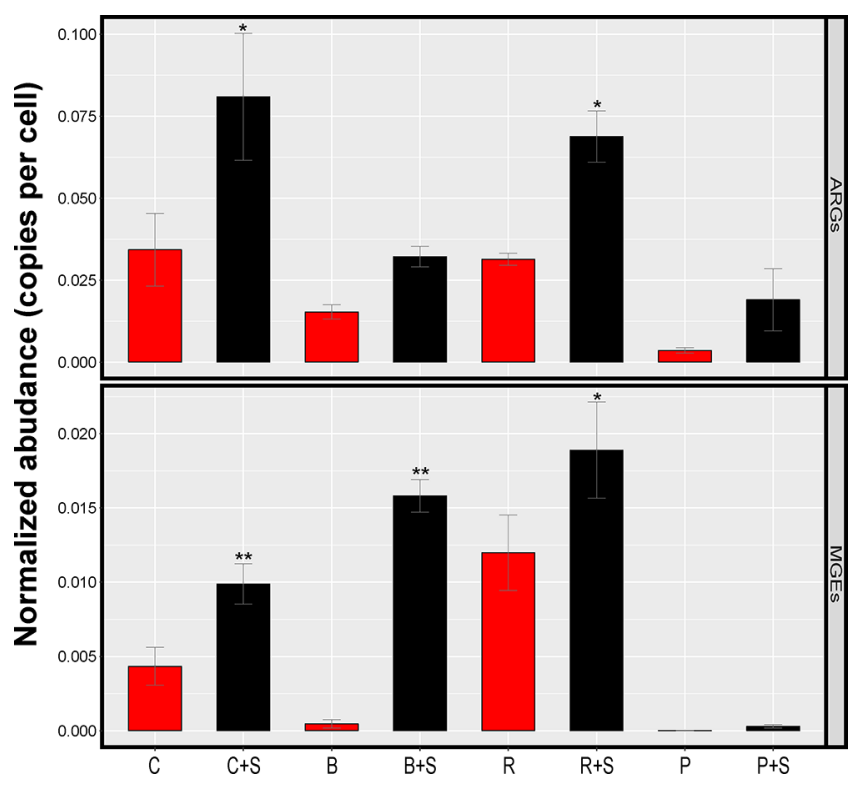

Figure 2. Normalized abundance of ARG and MGE. ** $(P<0.01)$ and $*(P<0.05)$ on the bar indicated that the application of struvite significantly increased the ARGs and MEGs abundance. $C$, nonplanted soil; $\mathrm{C}+\mathrm{S}$, nonplanted soil amended with struvite; $\mathrm{B}$, bulk soil; $\mathrm{B}+\mathrm{S}$, bulk soil amended with struvite; $R$, rhizosphere soil; $R+S$, rhizosphere soil amended with struvite; P, Brassica phyllosphere; $\mathrm{P}+\mathrm{S}$, Brassica phyllosphere planted in soil amended with struvite. Data shown in the figure are from three replicates $(n=3)$ and represented as means \pm SD.

integrase gene (intl-1) only found on the phyllosphere, but not detectable in soil or struvite, indicating these genes may be possible phyllosphere specialists; (vi) 30 genes shared by struvite and phyllosphere but not in soil. These genes are clear candidates transferring from struvite to edible plants and are the genes of concern here. These genes include 1 transposase gene (Tp614) and 29 ARGs which confer resistance to aminoglycoside, beta-lactams, MLSB, multidrug, sulfonamide and tetracycline. Among the 29 ARGs, some genes such as tetC, tetD, $q a c H, a c r B, a a d D, a p h A 1$, and $e m r B$, have a relatively higher abundance than others, indicating a potentially higher risk to human health posed by them; (vii) twenty-seven genes among all three compartments. Although it is not possible to tell if their presence on the phyllosphere is from struvite or soil but still are the genes of concern. These genes include 2 MGEstnpA-04 and intl-1 (clinic) and 25 ARGs, most of which confer resistance to aminoglycoside, multidrug, beta-lactams and tetracycline.

Bacterial Community Composition and Structure. After assembling and quality filtering, a total of 7892274 high quality sequences were obtained from all samples. By clustering OTUs at $3 \%$ dissimilarity level, we obtained a total of 92 205, 101 532, 127565 , and 9570 OTUs in nonplanted soil, bulk soil, rhizosphere soil, and phyllosphere, respectively. Rarefaction curves of OTUs showed samples from rhizosphere had the highest bacterial diversity, followed by bulk soil, nonplanted soil and phyllosphere. In addition, the application of struvite significantly increased the bacterial diversity in rhizosphere $(P<0.05)$, but not in bulk soil or phyllosphere. These result were further confirmed by evaluation of Chaol estimator, Phylogenetic diversity metrics (PD whole tree) and Shannon diversity index (SI Figure S5). PCoA analysis based on the Bray-Curtis distance (SI Figure S2) revealed a significant shift (Adonis test, $P<0.01$ ) between phyllosphere and soil samples along with PC1 (explained $44.30 \%$ of the total variance). Nonplanted soil was separated from bulk soil and rhizosphere soil along with PC2 (10.02\% of the total variance). These results indicated a larger shift of bacterial profile between phyllosphere and soil than that between different soil types. Difference of taxonomic compositions of bacteria between soils

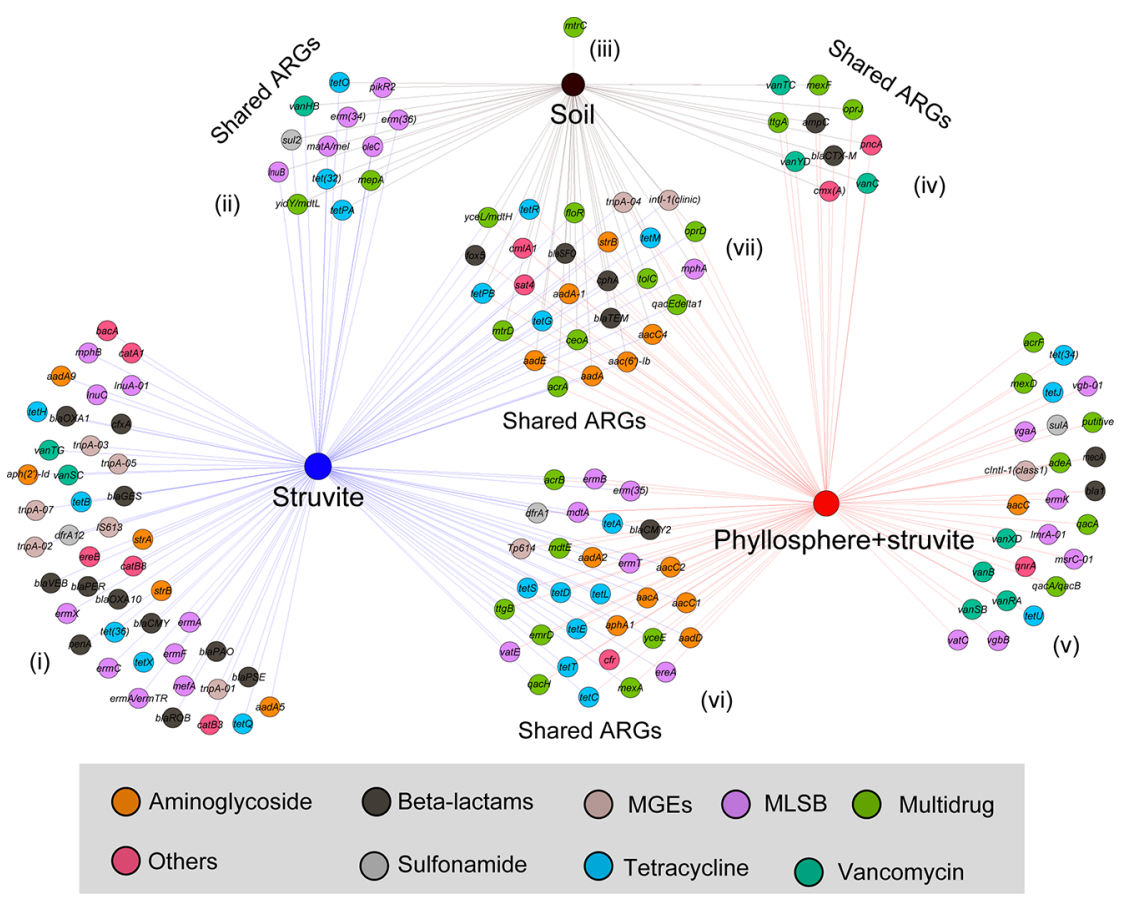

Figure 3. Bipartite network analysis revealing the shared ARGs and MGEs between struvite, soil (nonplanted soil without struvite), and phyllosphere of Brassica planted in soil amend with struvite. 


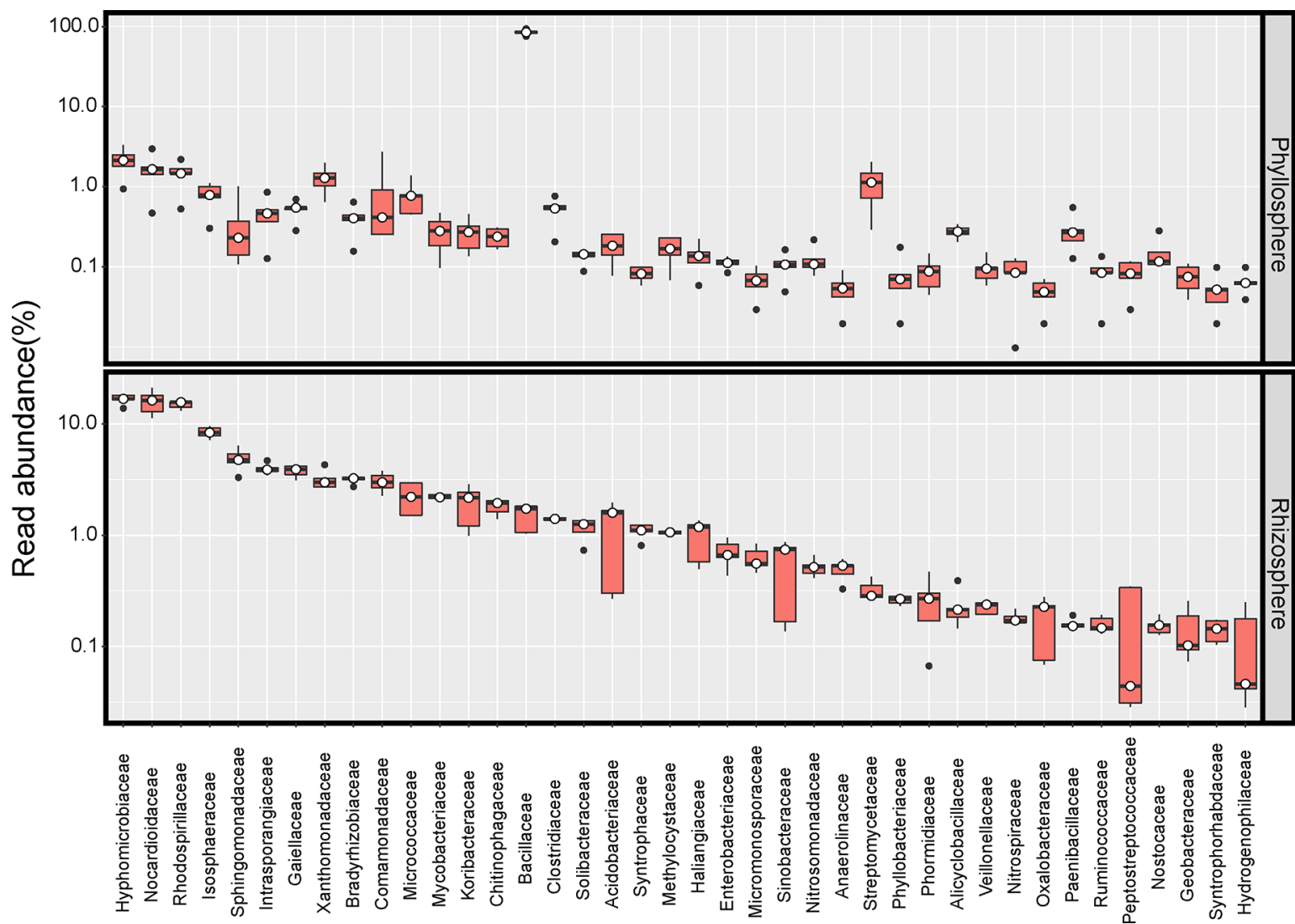

Figure 4. Boxplot of the abundance of the top 40 shared family level OTUs between phyllosphere and rhizosphere.

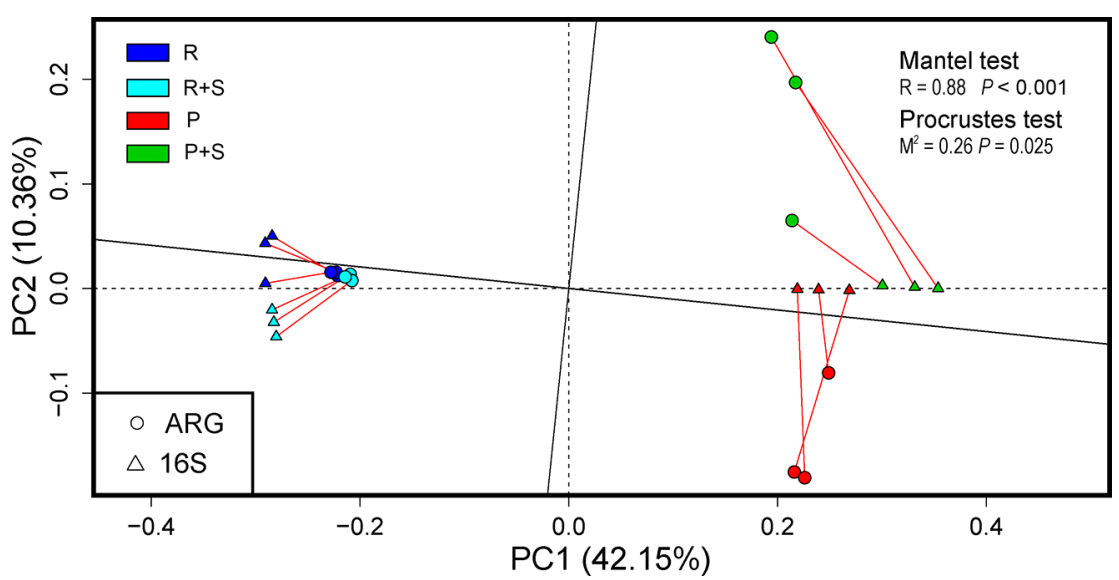

Figure 5. Procrustes test depicting the significant correlation between ARGs contents and shared bacterial taxa composition (16S rRNA gene OTUs data) based on the Bray-Curtis dissimilarity metrics (sum of squares $M^{2}=0.26, r=0.86, P=0.025$, 9999 permutations). $R$, rhizosphere soil; $R+S$, rhizosphere soil amended with struvite; $P$, Brassica phyllosphere; $P+S$, Brassica phyllosphere planted in soil amended with struvite.

and phyllosphere can be clearly visualized based on taxonomic affiliation using UCLUST-based consensus taxonomy classifier (SI Figure S6). For example, in soil samples, Proteobacteria and Actinobacteria were the most abundant phyla, with the percentage ranging from $37.34 \%$ to $42.57 \%$ and $16.24 \%$ to $21.83 \%$ respectively. While in phyllosphere samples, the most abundant phyla shifted to Firmicutes and Proteobacteria.

Shared OTUs between Rhizosphere and Phyllosphere and the Association with Antibiotic Resistome. A total of 303 OTUs (including 13 phyla) were shared (SI Figure S7) between rhizosphere and phyllosphere, accounting for $52.08 \%$ and $72.65 \%$ of the total reads in rhizosphere and phyllosphere, respectively. The top 40 shared family level OTUs were provided in Figure 4, and displayed in the order from the most to lest abundance in rhizosphere. The relative abundance of the shared bacteria was found to be significantly different between rhizosphere and phyllosphere. For example, Hyphomicrobiaceae, Nocardioidaceae, and Rhodospirillaceae were the most abundant families ( $20 \%$ of all reads) in rhizosphere, while their abundance was lower than $5 \%$ in phyllosphere, instead, the dominant family in phyllosphere was Bacillaceae which alone occupied $84.16 \%$ of all reads.

To investigate whether the shared OTUs correlated with the resistome composition, we used Mantel test and Procrustes 
analysis to correlate shared OTUs with resistome from rhizosphere and phyllosphere samples (Figure 5). Our results showed that ARG profiles were significantly correlated to the shared bacterial composition and structures (Mantel test, $R=$ $0.88, P<0.001)$. Procrustes analysis indicated that the ARG HT-qPCR data and shared bacterial $16 \mathrm{~S}$ rRNA gene OTUs can be clustered by the type of sample and exhibited a goodness-offit test (sum of squares $M^{2}=0.26, r=0.86, P=0.0025$, 9999 permutations) on the basis of Bray-Curtis dissimilarity metrics (Figure 5).

\section{DISCUSSION}

Impacts of Struvite Application on the Profile of Resistome. In the present study, we found a much higher level of ARGs in struvite than soil, and the application of struvite increased both the abundance and diversity of resistome in soil, rhizosphere, and phyllosphere of Brassica, confirming that struvite recycled from wastewater as fertilizer can increase the dissemination of resistome into environment. This agrees with previous observations that amendment with organic fertilizer (e.g., animals manure and sewage sludge) accelerated the spread of ARG into agricultural fields and plants, ${ }^{5,51}$ especially some vegetables such as lettuce, carrots, radish, tomatoes, and endive. $1^{10,12,37}$

By using culture-dependent methods, many antibiotic resistant bacteria have been detected on vegetables produced conventionally or organically. For instance, Ruimy et al. observed that the conventionally and organically produced fruits and vegetables contained equivalent counts of Gramnegative bacteria with extended-spectrum $\beta$-lactamase (ESBL) phenotype. ${ }^{52}$ Similar results were also reported by Rahube et al. by finding no consistently significant impacts of sewage sludge application on the abundance of total antibiotic-resistant coliform bacteria on vegetables. ${ }^{11}$ Considering that phenotype is the result of interaction between genotype and environment and also object of natural selection, ${ }^{53}$ culture-dependent results could be different from our study using molecular methods. Nevertheless, both methods have advantages and disadvantages. A combination of two methods in the future studies will give a better understanding of resistome in the environment.

Horizontal Gene Transfer. In this study, the increase of MGEs (including integrase and transposons genes) and the cooccurrence pattern between ARGs and MGEs in soil and phyllosphere (SI Figure S4), suggested that the application of struvite might facilitate the propagation and spread of ARGs via horizontal gene transfer. Intrinsically, ARGs are present in the chromosomes of environmental bacteria, but are now present in plasmids under selection pressure from antibiotics. ${ }^{54}$ Under these conditions, they can be transferred between nonpathogens, pathogens, and even distantly related organisms, such as Gram-positive and Gram-negative bacteria, through horizontal gene transfer. ${ }^{13,14}$ Therapeutic potential of antibiotics against pathogens may be compromised as the likelihood of pathogens to acquire resistance increases. Previous study had demonstrated that the phyllosphere of plants was conductive to conjugative plasmid transfer and thus dissemination of antibiotic resistance. ${ }^{55,56}$ In the present study, because of the limited number of MGEs included and lack of plasmid specific genes, evidence was not sufficient enough to conclude that struvite application increased the horizontal transfer of ARG. More studies are needed to give a more direct evidence of horizontal gene transfer in phyllosphere.
Pathway of ARGs from Struvite to Phyllosphere. The key finding of this study was the identification of shared ARGs and MGEs in struvite, soil and phyllosphere. Of most concern were the 30 genes shared exclusively by phyllosphere and struvite, since these genes were the clear candidate ARGs transferring from struvite to phyllosphere. More importantly, these genes included 1 transposons gene (Tp616) and 29 ARGs conferring resistance to the most commonly used antibiotics in human and animals, such as aminoglycoside, beta-lactams, MLSB, multidrug, sulfonamide, and tetracycline. Consumption of struvite-fertilized leafy vegetable may provide an exposure route for these clinical isolates-related ARGs to transfer to pathogenic bacteria, posing risk to human health. Fortunately, vancomycin as the last line of defense in the treatment of nosocomial infections by multiple drug-resistant strains of Gram-positive bacteria, ${ }^{57}$ was not on the list.

In addition, 303 OTUs were shared between rhizosphere and phyllosphere of Brassica. A recent study reported similar results that microbiota of leaves and flowers of grapevines shared a large proportion of taxa with soil bacterial communities. ${ }^{58}$ Furthermore, some functional genes and ARGs have also been detected in both phyllosphere and rhizosphere. ${ }^{59,60}$ For example, dinitrogen reductase and dinitrogenase have been detected in both phyllosphere and rhizosphere metagenome, indicating a functional overlap between leaf and root microbiota. ${ }^{59,60}$ Our previous study demonstrated that sulI, sulII, tetC, and tet $\mathrm{G}$ were detectable in both endophytes (root and leaf) and phyllosphere of lettuce and endive grown in manured soil. $^{37}$ The presence of shared taxa and shared genes indicated that root and leaf microbiota might interconnect and bacteria including antibiotic resistant bacteria could move between rhizosphere and phyllosphere. ${ }^{61-64}$ It has also been suggested that roots can recruit soil bacteria to survive inside the root, ${ }^{65,66}$ allowing ARGs to transfer from soil into the roots and surface of plants. This might be an important pathway to transfer resistome between organic fertilizer and plants. To fully elucidate the pathway, more rigorous time-series studies are needed in the future.

Health Risk Assessment and Potential solutions. Consumption of leafy vegetables represents a significant route for human exposure to antibiotic resistant bacteria and resistance genes that are naturally present in soil. ${ }^{10,67}$ It has been demonstrated that the abundance and the mobility of ARGs in agricultural soils can be enhanced by the application of organic matter. ${ }^{5,68}$ Ingestion of antibiotic resistant bacteria naturally found in soil is inevitable through consumption of vegetables and fruits. The benefits of eating raw product may be far outweighing any concern from exposure to natural soil bacteria. ${ }^{10}$ Nonetheless, we suggest that antibiotic resistance transfer via vegetables represents a potential risk to human health and it should be assessed and managed. Washing could be an effective way to eliminate potential antibiotic resistant bacteria on the surface of vegetables. Another way to reduce the potential risk is a period delay between application of organic fertilizer and crop harvest. A previous study suggested that sewage sludge have the potential to increase the variety and abundance of ARGs on vegetables harvested in the season of application but not in the subsequent season. ${ }^{11}$ Thus, a period delay (e.g., a year or a season) appears to be sufficient to attenuate exposure to organic fertilizer-borne ARGs. Since the diversity and abundance of resistome can vary among different organic fertilizers, the results reported by Rahube et al. might not be presentative of all organic fertilizers including struvite. 
Therefore, future work is needed to evaluate the field behavior of microorganisms and ARGs after application of organic fertilizer. The offset times between application of organic fertilizer and harvest also need to be validated under different environment circumstances to ensure a sufficient length to protect crop quality from antibiotic resistance. In addition, more studies are required to determine the efficacy of waste treatment practices and to optimize the process of waste disposal to eliminate the possible antibiotic resistant bacteria derived from waste stream before field application.

In summary, this study revealed that the application of struvite increased the abundance and diversity of resistome in soil, rhizosphere and phyllosphere of Brassica. The shared ARGs between struvite and phyllosphere suggested that struvite could be an important source of resistome in phyllosphere. These shared genes are commonly found in clinical isolates, indicating a potential health risk of using struvite as fertilizer. Furthermore, the identified shared OTUs between rhizosphere and phyllosphere and significant correlation between shared OTUs and resistome indicated that leaf- and root-associated microbiota might interconnect, ${ }^{61,63,64}$ and resistome may transfer from struvite to phyllosphere via rhizosphere using bacteria as the carrier. These findings are important for the evaluation of public health risks associated with vegetables grown in soils amended with struvite and highlight the necessity to take antibiotic resistance into consideration during the biologically active waste disposal.

\section{ASSOCIATED CONTENT}

\section{S Supporting Information}

The Supporting Information is available free of charge on the ACS Publications website at DOI: 10.1021/acs.est.7b01420.

Table S1. Chemical properties of struvite and soil. Table S2. Common topological properties used in network analysis. Table S3. List of primers used in this study. Figure S1. Schematic of experiment design. Figure S2. Principal coordinate analysis (PCoA) based on the Bray-Curtis distance showing the overall distribution pattern of ARGs (A) and bacterial community (B). Figure S3. Absolute abundance of ARGs and MGEs. Figure S4. Network analysis revealing the co-occurrence patterns among ARGs and MGEs subtypes. Figure S5. Alpha-diversity of bacterial community of all the samples, the corresponding diversity values are at a sequencing depth of 11,000. Figure S6. Bacterial taxonomic composition in soil and phyllosphere, at phylum (A), class (B), order (C) and family (D) level. Figure S7. Shared phyla between rhizosphere and phyllosphere (PDF)

\section{AUTHOR INFORMATION}

\section{Corresponding Author}

*Phone: +86-592-6190560; fax: +86-592-6190514; e-mail: lcui@iue.ac.cn.

\section{ORCID $\odot$}

Yong-Guan Zhu: 0000-0003-3861-8482

Li Cui: 0000-0002-0708-8899

\section{Notes}

The authors declare no competing financial interest.

\section{ACKNOWLEDGMENTS}

This research was funded by the Strategic Priority Research Program of Chinese Academy of Sciences (XDB15020402, XDB15020302,), the National Natural Science Foundation of China (21210008, 41571130063), and the International Science \& Technology Cooperation Program of China (2011DFB91710).

\section{REFERENCES}

(1) Laxminarayan, R.; Duse, A.; Wattal, C.; Zaidi, A. K.; Wertheim, H. F.; Sumpradit, N.; Vlieghe, E.; Hara, G. L.; Gould, I. M.; Goossens, H.; Greko, C.; So, A. D.; Bigdeli, M.; Tomson, G.; Woodhouse, W.; Ombaka, E.; Peralta, A. Q.; Qamar, F. N.; Mir, F.; Kariuki, S.; Bhutta, Z. A.; Coates, A.; Bergstrom, R.; Wright, G. D.; Brown, E. D.; Cars, O. Antibiotic resistance-the need for global solutions. Lancet Infect. Dis. 2013, 13, 1057-98.

(2) Neu, H. C. The Crisis in Antibiotic-Resistance. Science 1992, 257, 1064-1073.

(3) French, G. L. The continuing crisis in antibiotic resistance. Int. J. Antimicrob. Agents 2010, 36, S3-S7.

(4) Fahrenfeld, N.; Knowlton, K.; Krometis, L. A.; Hession, W. C.; Xia, K.; Lipscomb, E.; Libuit, K.; Green, B. L.; Pruden, A. Effect of manure application on abundance of antibiotic resistance genes and their attenuation rates in soil: field-scale mass balance approach. Environ. Sci. Technol. 2014, 48, 2643-50.

(5) Chen, Q.; An, X.; Li, H.; Su, J.; Ma, Y.; Zhu, Y. G. Long-term field application of sewage sludge increases the abundance of antibiotic resistance genes in soil. Environ. Int. 2016, 92-93, 1-10.

(6) Cheng, W.; Chen, H.; Su, C.; Yan, S. Abundance and persistence of antibiotic resistance genes in livestock farms: a comprehensive investigation in eastern China. Environ. Int. 2013, 61, 1-7.

(7) Tang, X.; Lou, C.; Wang, S.; Lu, Y.; Liu, M.; Hashmi, M. Z.; Liang, X.; Li, Z.; Liao, Y.; Qin, W.; Fan, F.; Xu, J.; Brookes, P. C. Effects of long-term manure applications on the occurrence of antibiotics and antibiotic resistance genes (ARGs) in paddy soils: Evidence from four field experiments in south of China. Soil Biol. Biochem. 2015, 90, 179-187.

(8) Joy, S. R.; Bartelt-Hunt, S. L.; Snow, D. D.; Gilley, J. E.; Woodbury, B. L.; Parker, D. B.; Marx, D. B.; Li, X. Fate and transport of antimicrobials and antimicrobial resistance genes in soil and runoff following land application of swine manure slurry. Environ. Sci. Technol. 2013, 47, 12081-8.

(9) Xie, W. Y.; McGrath, S. P.; Su, J. Q.; Hirsch, P. R.; Clark, I. M.; Shen, Q.; Zhu, Y. G.; Zhao, F. J. Long-Term Impact of Field Applications of Sewage Sludge on Soil Antibiotic Resistome. Environ. Sci. Technol. 2016, 50, 12602-12611.

(10) Marti, R.; Scott, A.; Tien, Y. C.; Murray, R.; Sabourin, L.; Zhang, Y.; Topp, E. Impact of manure fertilization on the abundance of antibiotic-resistant bacteria and frequency of detection of antibiotic resistance genes in soil and on vegetables at harvest. Appl. Environ. Microbiol. 2013, 79, 5701-9.

(11) Rahube, T. O.; Marti, R.; Scott, A.; Tien, Y. C.; Murray, R.; Sabourin, L.; Zhang, Y.; Duenk, P.; Lapen, D. R.; Topp, E. Impact of fertilizing with raw or anaerobically digested sewage sludge on the abundance of antibiotic-resistant coliforms, antibiotic resistance genes, and pathogenic bacteria in soil and on vegetables at harvest. Appl. Environ. Microbiol. 2014, 80, 6898-907.

(12) Zhu, B.; Chen, Q.; Chen, S.; Zhu, Y. G. Does organically produced lettuce harbor higher abundance of antibiotic resistance genes than conventionally produced? Environ. Int. 2017, 98, 152-159.

(13) Gillings, M. R. Lateral gene transfer, bacterial genome evolution, and the Anthropocene. Ann. N. Y. Acad. Sci. 2017, 1389, 20-36.

(14) Pruden, A.; Pei, R.; Storteboom, H.; Carlson, K. H. Antibiotic resistance genes as emerging contaminants: Studies in northern Colorado. Environ. Sci. Technol. 2006, 40, 7445-7450.

(15) Gell, K.; Ruijter, F. J. d.; Kuntke, P.; Graaff, M. d.; Smit, A. L. Safety and Effectiveness of Struvite from Black Water and Urine as a Phosphorus Fertilizer. J. Agr. Sci. 2011, 3, 67-80. 
(16) Antonini, S.; Arias, M. A.; Eichert, T.; Clemens, J. Greenhouse evaluation and environmental impact assessment of different urinederived struvite fertilizers as phosphorus sources for plants. Chemosphere 2012, 89, 1202-10.

(17) Plaza, C.; Sanz, R.; Clemente, C.; Fernandez, J. M.; Gonzalez, R.; Polo, A.; Colmenarejo, M. F. Greenhouse evaluation of struvite and sludges from municipal wastewater treatment works as phosphorus sources for plants. J. Agric. Food Chem. 2007, 55, 8206-8212.

(18) Huang, H.; Liu, J.; Jiang, Y. Crystallization and precipitation of phosphate from swine wastewater by magnesium metal corrosion. Sci. Rep. 2015, 5, 16601.

(19) Liu, X.; Tao, Y.; Wen, G.; Kong, F.; Zhang, X.; Hu, Z. Influence of Soil and Irrigation Water $\mathrm{pH}$ on the Availability of Phosphorus in Struvite Derived from Urine through a Greenhouse Pot Experiment. J. Agric. Food Chem. 2016, 64, 3324-9.

(20) Cordell, D.; Drangert, J. O.; White, S. The story of phosphorus: Global food security and food for thought. Global. Environ. Chang. 2009, 19, 292-305.

(21) Xie, J.; Lin, Y.; Li, C. J.; Wu, D. Y.; Kong, H. N. Removal and recovery of phosphate from water by activated aluminum oxide and lanthanum oxide. Powder Technol. 2015, 269, 351-357.

(22) Hutnik, N.; Kozik, A.; Mazienczuk, A.; Piotrowski, K.; Wierzbowska, B.; Matynia, A. Phosphates (V) recovery from phosphorus mineral fertilizers industry wastewater by continuous struvite reaction crystallization process. Water Res. 2013, 47, 3635-43.

(23) Hao, X.; Wang, C.; van Loosdrecht, M. C.; Hu, Y. Looking beyond struvite for P-recovery. Environ. Sci. Technol. 2013, 47, 49656.

(24) Moerman, W.; Carballa, M.; Vandekerckhove, A.; Derycke, D.; Verstraete, W. Phosphate removal in agro-industry: pilot- and full-scale operational considerations of struvite crystallization. Water Res. 2009, 43, 1887-92.

(25) Doyle, J. D.; Parsons, S. A. Struvite formation, control and recovery. Water Res. 2002, 36, 3925-40.

(26) Le Corre, K. S.; Valsami-Jones, E.; Hobbs, P.; Parsons, S. A. Phosphorus Recovery from Wastewater by Struvite Crystallization: A Review. Crit. Rev. Environ. Sci. Technol. 2009, 39, 433-477.

(27) Di Cesare, A.; Eckert, E. M.; D’Urso, S.; Bertoni, R.; Gillan, D. C.; Wattiez, R.; Corno, G. Co-occurrence of integrase 1, antibiotic and heavy metal resistance genes in municipal wastewater treatment plants. Water Res. 2016, 94, 208-14.

(28) McKinney, C. W.; Loftin, K. A.; Meyer, M. T.; Davis, J. G.; Pruden, A. tet and sul Antibiotic Resistance Genes in Livestock Lagoons of Various Operation Type, Configuration, and Antibiotic Occurrence. Environ. Sci. Technol. 2010, 44, 6102-6109.

(29) Brooks, J. P.; Adeli, A.; McLaughlin, M. R. Microbial ecology, bacterial pathogens, and antibiotic resistant genes in swine manure wastewater as influenced by three swine management systems. Water Res. 2014, 57, 96-103.

(30) Wang, J.; Ben, W.; Yang, M.; Zhang, Y.; Qiang, Z. Dissemination of veterinary antibiotics and corresponding resistance genes from a concentrated swine feedlot along the waste treatment paths. Environ. Int. 2016, 92-93, 317-23.

(31) Ye, Z.-L.; Deng, Y.; Lou, Y.; Ye, X.; Zhang, J.; Chen, S. Adsorption behavior of tetracyclines by struvite particles in the process of phosphorus recovery from synthetic swine wastewater. Chem. Eng. J. 2017, 313, 1633-1638.

(32) Zhu, Y.-G.; Johnson, T. A.; Su, J.-Q.; Qiao, M.; Guo, G.-X.; Stedtfeld, R. D.; Hashsham, S. A.; Tiedje, J. M. Diverse and abundant antibiotic resistance genes in Chinese swine farms. Proc. Natl. Acad. Sci. U. S. A. 2013, 110, 3435-3440.

(33) Ye, Z. L.; Chen, S. H.; Wang, S. M.; Lin, L. F.; Yan, Y. J.; Zhang, Z. J.; Chen, J. S. Phosphorus recovery from synthetic swine wastewater by chemical precipitation using response surface methodology. $J$. Hazard. Mater. 2010, 176, 1083-8.

(34) Luo, Y.; Xu, L.; Rysz, M.; Wang, Y.; Zhang, H.; Alvarez, P. J. Occurrence and transport of tetracycline, sulfonamide, quinolone, and macrolide antibiotics in the Haihe River Basin, China. Environ. Sci. Technol. 2011, 45, 1827-33.
(35) Ryu, H. D.; Lim, C. S.; Kang, M. K.; Lee, S. I. Evaluation of struvite obtained from semiconductor wastewater as a fertilizer in cultivating Chinese cabbage. J. Hazard. Mater. 2012, 221-222, 24855.

(36) Nie, S.; Li, H.; Yang, X.; Zhang, Z.; Weng, B.; Huang, F.; Zhu, G. B.; Zhu, Y. G. Nitrogen loss by anaerobic oxidation of ammonium in rice rhizosphere. ISME J. 2015, 9, 2059-67.

(37) Fang, H.; Wang, H.; Cai, L.; Yu, Y. Prevalence of antibiotic resistance genes and bacterial pathogens in long-term manured greenhouse soils as revealed by metagenomic survey. Environ. Sci. Technol. 2015, 49, 1095-104.

(38) Xie, W. Y.; Su, J. Q.; Zhu, Y. G. Phyllosphere bacterial community of floating macrophytes in paddy soil environments as revealed by illumina high-throughput sequencing. Appl. Environ. Microbiol. 2015, 81, 522-32.

(39) Klappenbach, J. A.; Saxman, P. R.; Cole, J. R.; Schmidt, T. M. rrndb: the Ribosomal RNA Operon Copy Number Database. Nucleic. Acids. Res. 2001, 29, 181-4.

(40) Stalder, T.; Barraud, O.; Jove, T.; Casellas, M.; Gaschet, M.; Dagot, C.; Ploy, M. C. Quantitative and qualitative impact of hospital effluent on dissemination of the integron pool. ISME J. 2014, 8, 76877.

(41) Turner, S.; Pryer, K. M.; Miao, V. P. W.; Palmer, J. D. Investigating deep phylogenetic relationships among cyanobacteria and plastids by small submit rRNA sequence analysis. J. Eukaryotic Microbiol. 1999, 46, 327-338.

(42) Rastogi, G.; Sbodio, A.; Tech, J. J.; Suslow, T. V.; Coaker, G. L.; Leveau, J. H. Leaf microbiota in an agroecosystem: spatiotemporal variation in bacterial community composition on field-grown lettuce. ISME J. 2012, 6, 1812-22.

(43) Caporaso, J. G.; Kuczynski, J.; Stombaugh, J.; Bittinger, K.; Bushman, F. D.; Costello, E. K.; Fierer, N.; Pena, A. G.; Goodrich, J. K.; Gordon, J. I.; Huttley, G. A.; Kelley, S. T.; Knights, D.; Koenig, J. E.; Ley, R. E.; Lozupone, C. A.; McDonald, D.; Muegge, B. D.; Pirrung, M.; Reeder, J.; Sevinsky, J. R.; Turnbaugh, P. J.; Walters, W. A.; Widmann, J.; Yatsunenko, T.; Zaneveld, J.; Knight, R. QIIME allows analysis of high-throughput community sequencing data. Nat. Methods 2010, 7, 335-6.

(44) Edgar, R. C. Search and clustering orders of magnitude faster than BLAST. Bioinformatics 2010, 26, 2460-1.

(45) McDonald, D.; Price, M. N.; Goodrich, J.; Nawrocki, E. P.; DeSantis, T. Z.; Probst, A.; Andersen, G. L.; Knight, R; Hugenholtz, P. An improved Greengenes taxonomy with explicit ranks for ecological and evolutionary analyses of bacteria and archaea. ISME J. 2012, 6, $610-8$.

(46) Langille, M. G.; Zaneveld, J.; Caporaso, J. G.; McDonald, D.; Knights, D.; Reyes, J. A.; Clemente, J. C.; Burkepile, D. E.; Vega Thurber, R. L.; Knight, R.; Beiko, R. G.; Huttenhower, C. Predictive functional profiling of microbial communities using $16 \mathrm{~S}$ rRNA marker gene sequences. Nat. Biotechnol. 2013, 31, 814-21.

(47) Caporaso, J. G.; Bittinger, K.; Bushman, F. D.; DeSantis, T. Z.; Andersen, G. L.; Knight, R. PyNAST: a flexible tool for aligning sequences to a template alignment. Bioinformatics 2010, 26, 266-267.

(48) Price, M. N.; Dehal, P. S.; Arkin, A. P. FastTree 2Approximately Maximum-Likelihood Trees for Large Alignments. PLoS One 2010, 5, e9490.

(49) RCoreTeam A Language and Environment for Statistical Computing; R Foundation for Statistical Computing: Vienna, Austria. 2014. http://www.R-project.org.

(50) Oksanen, J.; Blanchet, F. G.; Kindt, R.; Legendre, P.; Minchin, P. R.; O’Hara, R. B.; Simpson, G. L.; Solymos, P.; Steven, M. H. H.; Wagner, $\mathrm{H}$. vegan: Community Ecology Package. $\mathrm{R}$ package version 2.2-0. 2014. http://CRAN.R-project.org/package=vegan.

(51) Bondarczuk, K.; Markowicz, A.; Piotrowska-Seget, Z. The urgent need for risk assessment on the antibiotic resistance spread via sewage sludge land application. Environ. Int. 2016, 87, 49-55.

(52) Ruimy, R.; Brisabois, A.; Bernede, C.; Skurnik, D.; Barnat, S.; Arlet, G.; Momcilovic, S.; Elbaz, S.; Moury, F.; Vibet, M. A.; Courvalin, P.; Guillemot, D.; Andremont, A. Organic and conventional fruits and 
vegetables contain equivalent counts of Gram-negative bacteria expressing resistance to antibacterial agents. Environ. Microbiol. 2010, $12,608-15$

(53) Cavalli-Sforza, L. L.; Feldman, M. W. The Evolution of Continuous Variation. III. Joint Transmission of Genotype, Phenotype and Environment. Genetics 1978, 90, 391-425.

(54) D'Costa, V. M.; McGrann, K. M.; Hughes, D. W.; Wright, G. D. Sampling the antibiotic resistome. Science 2006, 311, 374-7.

(55) van Elsas, J. D.; Turner, S.; Bailey, M. J. Horizontal gene transfer in the phytosphere. New Phytol. 2003, 157, 525-537.

(56) Pontiroli, A.; Rizzi, A.; Simonet, P.; Daffonchio, D.; Vogel, T. M.; Monier, J. M. Visual evidence of horizontal gene transfer between plants and bacteria in the phytosphere of transplastomic tobacco. Appl. Environ. Microbiol. 2009, 75, 3314-22.

(57) Enright, M. C. The evolution of a resistant pathogen-the case of MRSA. Curr. Opin. Pharmacol. 2003, 3, 474-9.

(58) Zarraonaindia, I.; Owens, S. M.; Weisenhorn, P.; West, K.; Hampton-Marcell, J.; Lax, S.; Bokulich, N. A.; Mills, D. A.; Martin, G.; Taghavi, S.; van der Lelie, D.; Gilbert, J. A. The soil microbiome influences grapevine-associated microbiota. mBio 2015, 6, e02527-14.

(59) Bai, Y.; Muller, D. B.; Srinivas, G.; Garrido-Oter, R.; Potthoff, E.; Rott, M.; Dombrowski, N.; Munch, P. C.; Spaepen, S.; RemusEmsermann, M.; Huttel, B.; McHardy, A. C.; Vorholt, J. A.; SchulzeLefert, P. Functional overlap of the Arabidopsis leaf and root microbiota. Nature 2015, 528, 364-9.

(60) Knief, C.; Delmotte, N.; Chaffron, S.; Stark, M.; Innerebner, G.; Wassmann, R; von Mering, C.; Vorholt, J. A. Metaproteogenomic analysis of microbial communities in the phyllosphere and rhizosphere of rice. ISME J. 2012, 6, 1378-90.

(61) Bodenhausen, N.; Horton, M. W.; Bergelson, J. Bacterial communities associated with the leaves and the roots of Arabidopsis thaliana. PLoS One 2013, 8, e56329.

(62) Afzal, M.; Khan, Q. M.; Sessitsch, A. Endophytic bacteria: prospects and applications for the phytoremediation of organic pollutants. Chemosphere 2014, 117, 232-42.

(63) Ruiz-Perez, C. A.; Restrepo, S.; Zambrano, M. M. Microbial and Functional Diversity within the Phyllosphere of Espeletia Species in an Andean High-Mountain Ecosystem. Appl. Environ. Microbiol. 2016, 82, 1807-17.

(64) Beattie, G. A.; Lindow, S. E. Bacterial colonization of leaves: A spectrum of strategies. Phytopathology 1999, 89, 353-359.

(65) Lundberg, D. S.; Lebeis, S. L.; Paredes, S. H.; Yourstone, S.; Gehring, J.; Malfatti, S.; Tremblay, J.; Engelbrektson, A.; Kunin, V.; del Rio, T. G.; Edgar, R. C.; Eickhorst, T.; Ley, R. E.; Hugenholtz, P.; Tringe, S. G.; Dangl, J. L. Defining the core Arabidopsis thaliana root microbiome. Nature 2012, 488, 86-90.

(66) Bulgarelli, D.; Rott, M.; Schlaeppi, K.; Ver Loren van Themaat, E.; Ahmadinejad, N.; Assenza, F.; Rauf, P.; Huettel, B.; Reinhardt, R.; Schmelzer, E.; Peplies, J.; Gloeckner, F. O.; Amann, R.; Eickhorst, T.; Schulze-Lefert, P. Revealing structure and assembly cues for Arabidopsis root-inhabiting bacterial microbiota. Nature 2012, 488, 91-5.

(67) Sannes, M. R.; Belongia, E. A.; Kieke, B.; Smith, K.; Kieke, A.; Vandermause, M.; Bender, J.; Clabots, C.; Winokur, P.; Johnson, J. R. Predictors of antimicrobial-resistant Escherichia coli in the feces of vegetarians and newly hospitalized adults in Minnesota and Wisconsin. J. Infect. Dis. 2008, 197, 430-4.

(68) Udikovic-Kolic, N.; Wichmann, F.; Broderick, N. A.; Handelsman, J. Bloom of resident antibiotic-resistant bacteria in soil following manure fertilization. Proc. Natl. Acad. Sci. U. S. A. 2014, 111, 15202-7. 